\title{
An immunohistochemical study of branchial cysts
}

\author{
J CROCKER, RACHEL JENKINS
}

From the Histopathology Department, East Birmingham Hospital, Bordesley Green East, Birmingham

SUMMARY Twenty five specimens of branchial cyst from the same number of patients have been examined. On staining with haematoxylin and eosin a consistent finding was that the mural lymphoid follicles were always aligned with their mantle zones towards the luminal epithelium. With conventional staining lymphatic sinuses were noted in 17 of the specimens, but with immunohistochemical staining these structures were apparent in 23 cysts. Their frequent occurrence in branchial cysts supports the theory that these lesions are derived from epithelial inclusions in lymph nodes. Immunohistochemical techniques for a range of other markers, using polyclonal and monoclonal antisera, showed a distribution of lymphoid and non-lymphoid tissue elements, as seen in lymph nodes and, for example, palatine tonsils. The lining luminal epithelium also shared many features in common with the crypt epithelium of tonsils.

The nature of branchial cysts is uncertain, ${ }^{1}$ although suggestions of their origin include epithelial structures contained within lymph nodes and developmental defects. Recently, certain similarities have been shown between the epithelial lining of brachial cysts and the organisation of palatine tonsillar crypts. ${ }^{23}$ In an attempt to study the organisation of branchial cysts in more detail we have applied immunohistochemical procedures to a series of specimens with reference to both the lymphoid element and the lining epithelium.

\section{Material and methods}

BRANCHIAL CYSTS

Twenty five specimens from the same number of patients were studied. Patients' ages ranged from 19 to 43 years (mean 26 years). In four cases fresh tissue was available for study by means of frozen section techniques.

\section{FIXATION AND PROCESSING}

All specimens were fixed for $24-48 \mathrm{~h}$ in $10 \%$ formol-saline and then dehydrated and taken to paraffin wax. Sections were cut at 3-4 $\mu \mathrm{m}$, dewaxed, and taken to Tris buffer, $\mathrm{pH} 7 \cdot 6$, before immunostaining.

\section{IMMUNOHISTOCHEMISTRY}

Paraffin sections were stained by the peroxidaseantiperoxidase (PAP) technique for the following

Accepted for publication 28 February 1985 antigens: $\kappa$ and $\lambda$ immunoglobulin light chains; $\gamma, \alpha$, $\mu, \delta$, and $\epsilon$ immunoglobulin heavy chains; factor VIII related antigen; muramidase; $\alpha_{1}$-antitrypsin; and S-100 protein. The primary antisera used were polyclonal; they were raised in rabbits and obtained commercially from Mercia Brocades, Weybridge, Surrey, UK. The primary antisera were applied at suitable titres for $20 \mathrm{~min}$ after trypsinisation and blocking of endogenous peroxidase with the hydrochloric acid and methanol technique. After a thorough wash swine antirabbit antiserum was applied for $20 \mathrm{~min}$; this was followed by another wash in Tris buffer at $\mathrm{pH} \mathrm{7.6.} \mathrm{Rabbit} \mathrm{PAP} \mathrm{was} \mathrm{then}$ applied for a further $20 \mathrm{~min}$, followed by a final wash in buffer. The peroxidase was visualised by the usual 3,3'-diaminobenzidine (DAB) reaction, and the sections were counterstained in haematoxylin, washed, dehydrated, cleared, and mounted in synthetic medium.

In addition, polyclonal antisera to cathepsin $\mathrm{B}$, cathepsin G, and leucocyte elastase were applied. These were raised in sheep and generously supplied by the Immunodiagnostic Research Laboratory, University of Birmingham, UK. Trypsinisation was not used since it is either of no effect or is deleterious to staining for these antigens. ${ }^{4-6}$ An indirect method was used, 6 the primary antisera being stained by peroxidase conjugated, rabbit antisheep serum; the peroxidase was visualised by the DAB reaction. The sections were counterstained and mounted as described above. The usual controls (including preadsorption of the primary antisera with the specific antigen) were performed as 
described before.?

Frozen section material, available from four specimens, was submitted to staining for $\kappa$ and $\lambda$ immunoglobulin light chains and $\gamma, \alpha, \mu, \delta$, and $\epsilon$ immunoglobulin heavy chains, as described above. The sections were cut in a cryostat at 5-8 $\mu \mathrm{m}$ thickness and fixed in acetone at room temperature for $10 \mathrm{~min}$ and then allowed to dry in air. A variety of monoclonal antisera were also applied; these were directed against T1, T8 DRC-1, C3bR, and HLA-DR determinants (Mercian Brocades, Weybridge, Surrey, UK). The primary antisera were diluted $1 / 25$ and applied directly to the dry acetone fixed sections. The incubation time for the primary antisera was $30 \mathrm{~min}$ at $37^{\circ} \mathrm{C}$. The slides were washed well in Tris buffer ( $\mathrm{pH} \mathrm{7.6)}$ at the end of this period and then incubated (again for $30 \mathrm{~min}$ at $37^{\circ} \mathrm{C}$ ) with peroxidase conjugated antimouse immunoglobulins diluted $1 / 30$. This stage was followed by another wash in Tris buffer, and the peroxidase reaction was developed by the DAB reaction. The sections were counterstained in Mayer's haemalum for $15 \mathrm{~s}$, "blued" in running tap water, dehydrated, cleared, and mounted in synthetic medium. Tris buffer at $\mathrm{pH}$ $7 \cdot 6$ was used for all dilutions of antisera.

In the case of the monoclonal antiserum to common leucocyte antigen, the same procedure was adopted but was applied to paraffin, rather than frozen sections.

Table 1 lists the antisera used in this study.

\section{Results}

\section{FOLLICLES}

Follicles were present in varying numbers in all specimens. They showed a zonal pattern, the mantle zone of small lymphocytes always being orientated towards the luminal epithelium (Fig. 1).

Staining for cytoplasmic immunoglobulin heavy and light chains was positive, with more cells secreting $\kappa$ chains than those containing $\lambda$ chains (Fig. 2). Of the cells positive for heavy chains, those containing $\gamma$ chains were the most common, followed by

Table 1 Antisera used in the examination of branchial cysts

\begin{tabular}{ll}
\hline Polyclonal antisera to & Monoclonal antisera to \\
\hline$\kappa, \lambda$ chains & Common leucocyte antigen \\
$\gamma, \alpha, \mu, \delta, \epsilon$ chains & T1, T8 \\
Factor VIII related antigen & DRC-1 \\
Cathepsin B & HLA-DR \\
Cathepsin G & C3bR \\
Leucocyte elastase & \\
S-100 protein & \\
$\alpha$-antitrypsin & \\
Muramidase & \\
\hline
\end{tabular}

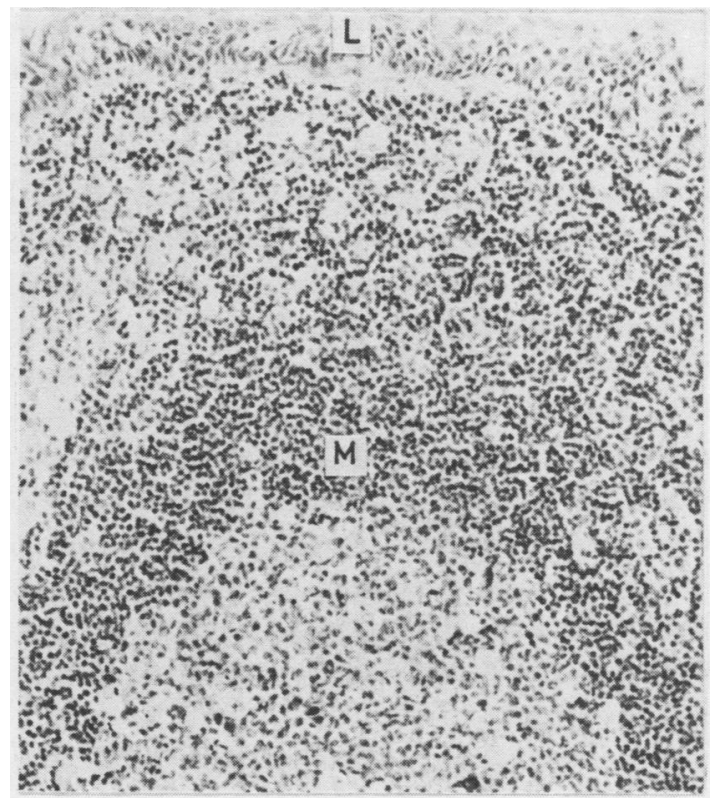

Fig. 1 A lymphoid follicle in a branchial cyst, showing orientation with the mantle zone $(M)$ lying towards the cyst lumen $(L)$. Haematoxylin and eosin; paraffin section. $\times$ 200.

cells containing $\alpha, \mu, \delta, \epsilon$ chains, in diminishing order of frequency. Cells containing $\epsilon$ chains were sparse, often being almost absent.

With frozen sections (and, occasionally, paraffin sections) there was a delicate network of activity, especially of $\kappa, \lambda$, and $\mu$ chains and less strongly for $\gamma$ and $\alpha$ chains in the follicle centres, corresponding to dendritic reticulum cells. The surfaces of the mantle zone cells were positive for $\delta$ chains (Fig. 3).

Cells in the follicles staining positively for $\mathrm{T} 1$ greatly outnumbered those staining for T8 determinant. A network of activity was seen in the follicle centres and mantle zones with antiserum to DRC-1 (Fig. 4) and C3bR. The HLA-DR antiserum also labelled the follicle centres and activity was seen in histiocytic reticulum cells.

Staining for cathepsin B, $\alpha_{1}$-antitrypsin and muramidase was seen only in histiocytic reticulum cells in follicle centres and there was no positivity for S-100 protein. Occasional granulocytes, staining positively for leucocyte elastase, muramidase, and cathepsin G, were seen. Blood vessels penetrating the follicles were positively stained with antiserum against factor VIII related antigen.

INTERFOLLICULAR AREAS

Scattered plasma cells containing $\kappa$ and $\lambda$ chains were present in these areas. In paraffin sections the 


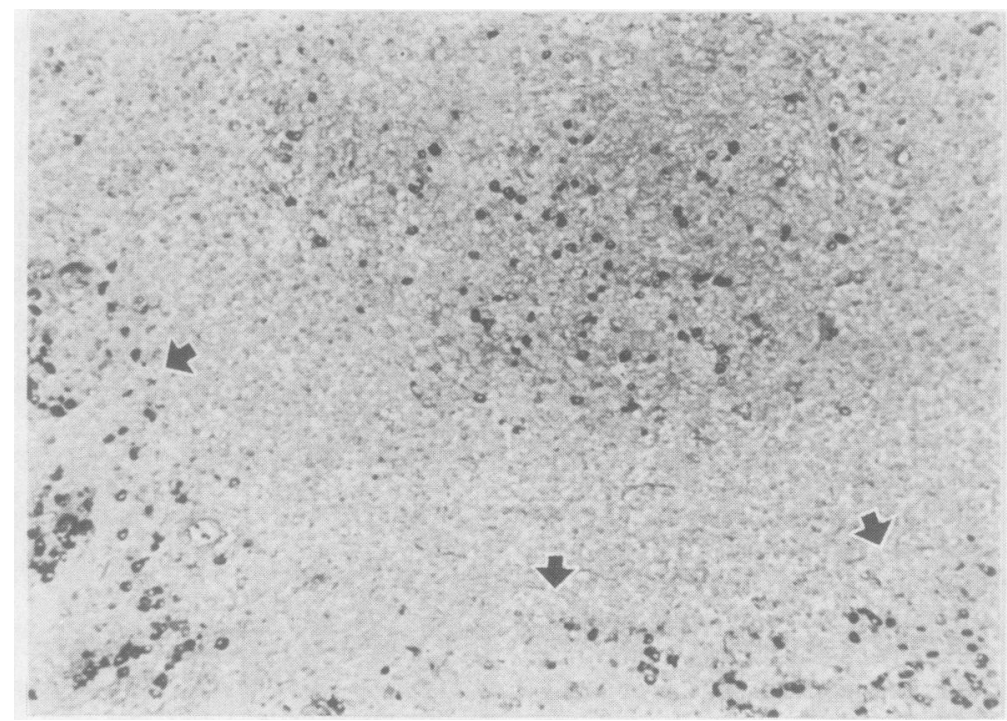

Fig. 2 Branchial cyst showing many cells containing $\kappa$ light chains within a follicle, centrally, and beneath the lining epithelium (arrows). PAP technique for $\kappa$ chains; paraffin section. $\times 180$.

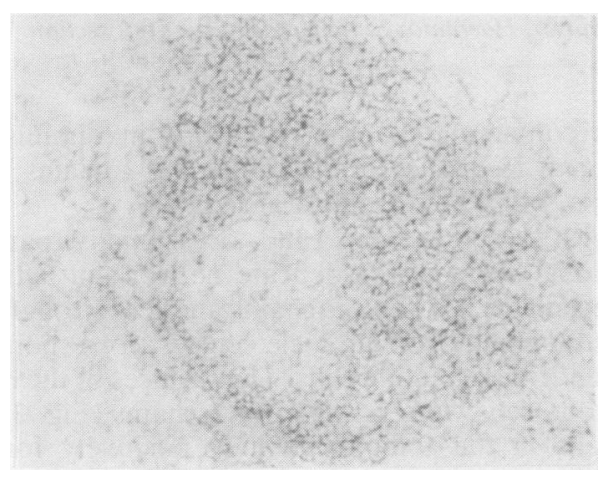

Fig. 3 Mantle zone lymphocytes in a lymphoid follicle from branchial cyst showing surface staining for $\delta$ heavy chains. PAP technique for $\delta$ chains; frozen section. $\times 140$.

former outnumbered the latter with a ratio of approximately $1 \cdot 5: 1 \cdot 0$. The number of cells containing $\gamma$ chains exceeded those containing $\mu$ and $\alpha$ chains. Few plasma cells containing $\delta$ or $\epsilon$ chains were seen. In frozen sections cells staining for surface $\kappa$ activity outnumbered those with surface $\lambda$ activity. Similarly, cells with surface activity for $\gamma$ chains were much more common that those possessing surface activity for the other heavy chains.

In cryostat sections, $T 1$ positive cells greatly outnumbered T8 positive lymphocytes. Activity for DRC-1 determinant was uniformly negative. Occa- sional branching cells stained for HLA-DR, but activity for C $3 \mathrm{bR}$ was rarely encountered, although some histiocytic reticulum cells were positive.

Around and between all follicles there was extensive activity for factor VIII related antigen within the endothelial lining of vascular structures, including high endothelial vessels. Cathepsin $B, \alpha_{1-}$ antitrypsin, and muramidase positive histiocytic reticulum cells were also present, as were many S-100 protein positive interdigitating cells. Occasional granulocytes, staining for leucocyte elastase, muramidase, and cathepsin $G$, were seen. In some areas these cells were strikingly common.

\section{EPITHELIAL LINING}

The epithelial cells themselves were negative for all markers apart from cathepsin B, which was present in small concentrations.

In paraffin sections occasional cells containing cytoplasmic immunoglobulin light and heavy chains were seen, although there was no definite pattern to their occurrence. The same was the case for cells possessing surface immunoglobulin.

Many T1 positive lymphocytes were present within the epithelium (Fig. 5); T8 bearing cells were present but less common.

In addition, in paraffin sections numerous $\mathrm{S}-100$ protein bearing cells were seen (Fig. 6). These were finely branching, in contrast to cathepsin B, muramidase, and $\alpha_{1}$-antitrypsin positive cells, which were generally rounded (Fig. 7). 


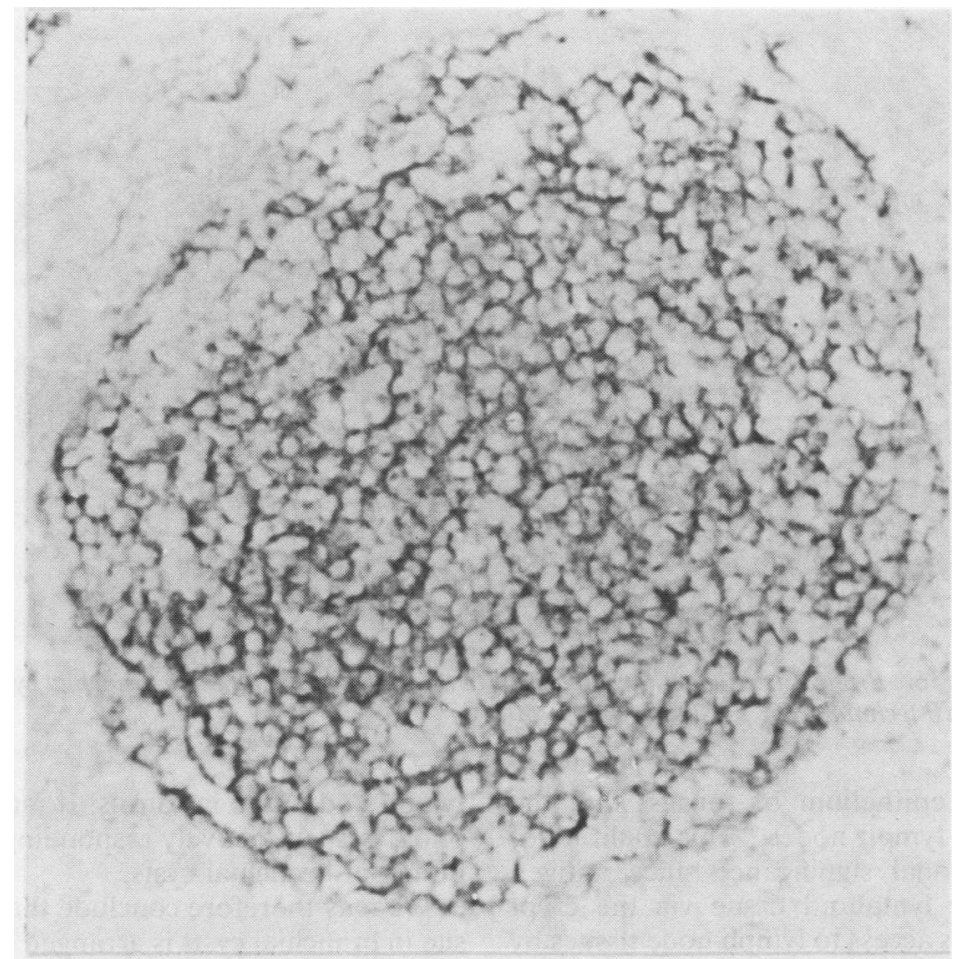

Fig. 4 Network of staining activity in centre of lymphoid follicle in branchial cyst. Monoclonal stain for DRC-1 determinant; frozen section. $\times 140$.

In some areas granulocytes were present within the epithelium; these were positive for cathepsin G, leucocyte elastase, and muramidase. Factor VIII related antigen positive blood vessels were often numerous just beneath the epithelium.

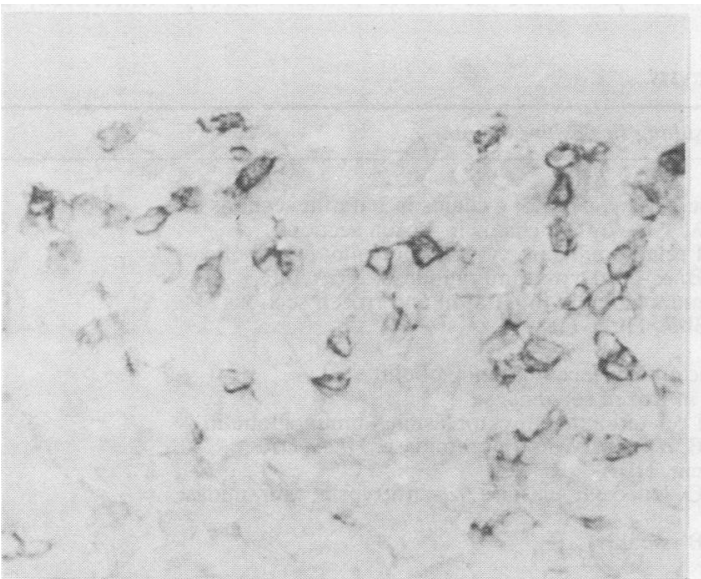

Fig. 5 T lymphocytes within the lining epithelium of a branchial cyst. Monoclonal stain for T-1 determinant; frozen section. $\times 500$.
LYMPHATIC SINUSES

In 17 of the specimens, examined as haematoxylin eosin stained sections, structures which corresponded to marginal lymphatic sinuses were seen beneath the capsule of the cyst. In addition, between the follicles there were further sinuses, resembling the intermediate or medullary sinuses of lymph nodes.

When immunostained for cathepsin B, $\alpha_{1-}$ antitrypsin, muramidase, and $\alpha$ chains such sinuses were seen in 23 of the specimens, the lining cells containing granular reaction product (Fig. 8). Weaker staining was seen with antiserum to $\gamma$ chain, but other antigens were absent.

\section{Discussion}

This study has shown certain similarities between the epithelial elements of branchial cysts and palatine tonsils and between the lymphoid tissue of branchial cysts and palatine tonsils and reactive lymph nodes.

The orientation of lymphoid follicles in branchial cysts (their mantle zones are directed towards the epithelium), is analogous with their direction 


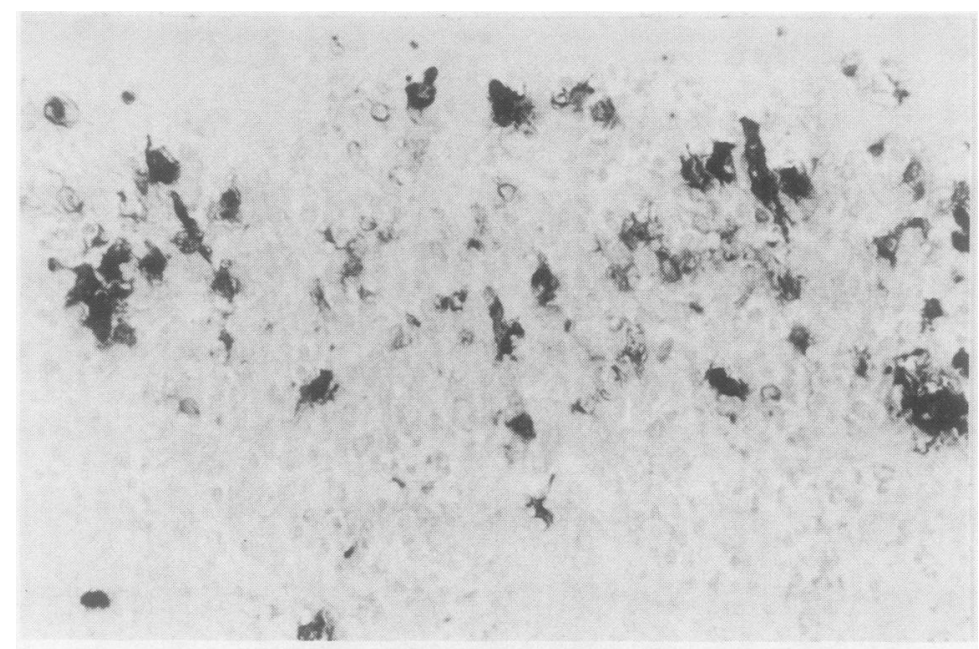

Fig. 6 Branching, Langerhans' like cells in the lining epithelium of a branchial cyst. $P A P$ technique for S-100 protein. $\times 500$.

towards the crypt epithelium of tonsils ${ }^{8}$ and the marginal sinuses in lymph nodes. ${ }^{9}$ This could be of considerable functional significance since antigen enters the tonsillar lymphoid tissue via the crypt epithelium and gains access to lymph node tissues by way of the marginal sinuses. Indeed, lack of such orientation and of a zonal pattern in follicles in follicular lymphomas may be related to the relative absence of sinuses in these neoplasms. ${ }^{9}$ The organisation of follicles and their centres in branchial cysts does not appear to be deranged since the distribution of dendritic and histiocytic reticulum cells and cells containing immunoglobulin light and heavy chains corresponds closely to those in reactive lymph nodes and in tonsils. It may be that the lymphoid tissue is actively responding to antigens in the lumen of branchial cysts.

We may therefore conclude that the lymphoid tissue in branchial cysts is arranged normally in a functional sense. This conclusion may also be extended to the interfollicular, $\mathrm{T}$ dependent areas, where normal distributions of component cells, including lymphocytes bearing $\mathrm{T} 1$ and $\mathrm{T} 8$ determinants, interdigitating, and histiocytic reticulum cells are seen. These areas are also highly vascular, containing many factor VIII related antigen positive blood vessels, as is the case in tonsils and lymph nodes. ${ }^{10}$ The presence of acute inflammatory infiltrates, as

Table 2 Tissue elements and staining responses in branchial cysts

\begin{tabular}{|c|c|}
\hline Site or cell type & Antisera resulting in positive staining \\
\hline $\begin{array}{l}\text { Lymphoid follicles } \\
\text { Immunocytes } \\
\text { Blood vessels } \\
\text { Histiocytic reticulum cells } \\
\text { Dendritic reticulum cells }\end{array}$ & $\begin{array}{l}\text { Cytoplasmic } \kappa, \lambda, \gamma, \alpha, \mu, \delta, \epsilon \text { chains in paraffin sections } \\
\text { Surface } \kappa, \lambda, \gamma, \alpha, \mu, \delta, \epsilon \text { chains in frozen sections } \\
\text { Factor VIII related antigen; cytoplasmic immunoglobulin } \\
\text { Cathepsin B, } \alpha \text {-antitrypsin, muramidase, HLA-DR } \\
\text { Surface immunoglobulin in paraffin and frozen sections } \\
\text { DRC-1, C3bR, HLA-DR }\end{array}$ \\
\hline $\begin{array}{l}\text { Interfollicular areas } \\
\text { Immunocytes } \\
\text { T lymphocytes } \\
\text { Blood vessels } \\
\text { Histiocytic reticulum cells } \\
\text { Interdigitating dendritic cells } \\
\text { Granulocytes } \\
\text { Luminal epithelium } \\
\text { Epithelial cells } \\
\text { T lymphocytes } \\
\text { Langerhans' cells } \\
\text { Histiocytic reticulum cells } \\
\text { Lymphatic sinuses } \\
\text { Sinus lining cells }\end{array}$ & $\begin{array}{l}\text { Cytoplasmic and surface immunoglobulin } \\
\text { T1 and T8 in frozen sections } \\
\text { Factor VIII related antigen; cytoplasmic immunoglobulin } \\
\text { Cathepsin B, } \alpha_{\text {-antitrypsin, muramidase, HLA-DR }} \\
\text { S-100 protein, HLA-DR } \\
\text { Cathepsin G, leucocyte elastase, } \alpha_{1} \text {-antitrypsin, muramidase } \\
\text { Cathepsin B (weakly) } \\
\text { T1 and T8 } \\
\text { S-100 } \\
\text { Cathepsin B, } \alpha_{1} \text {-antitrypsin, muramidase } \\
\text { Cathepsin B, } \alpha_{1} \text {-antitrypsin, muramidase, cytoplasmic immunoglobulin A }\end{array}$ \\
\hline
\end{tabular}




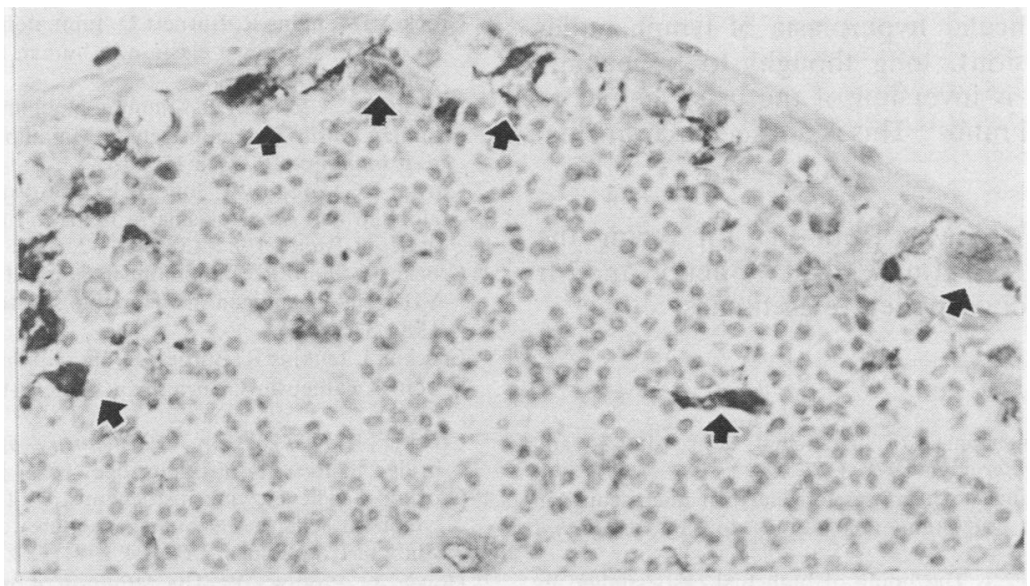

Fig. 7 Histiocytic reticulum cells (arrows) within and beneath the lining epithelium of a branchial cyst. Indirect method for cathepsin B. Original magnification $\times 320$.

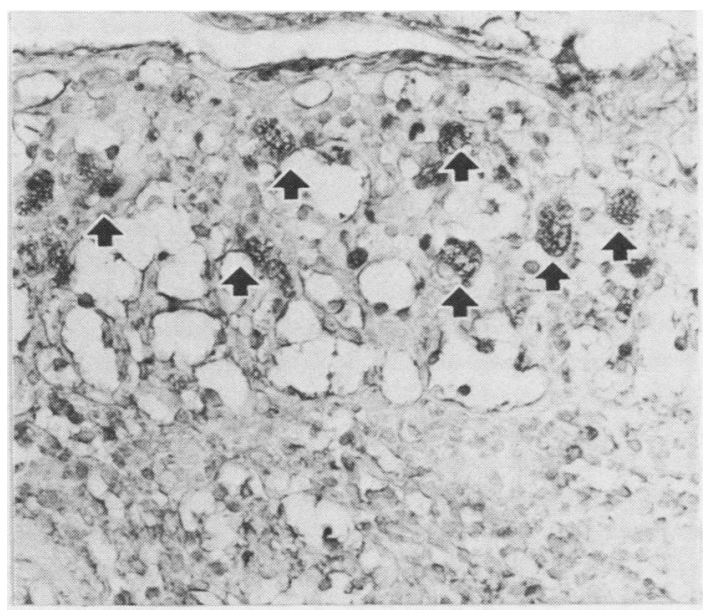

Fig. 8 Lining cells (arrows) of a lymphatic (marginal) sinus in a branchial cyst. Indirect method for cathepsin B. $\times$ 240.

shown by staining for cathepsin $\mathrm{G}^{11}$ and leucocyte elastase, ${ }^{7}$ is possibly accounted for by local infection or by physical irritation.

The findings in the branchial cyst lining epithelium have striking similarities with those in the crypt epithelium of palatine tonsils. The unusual morphology of these epithelia has previously been described by means of scanning and transmission electron ${ }^{2} 3$ microscopy and by enzyme histochemistry. ${ }^{312}$ The epithelium possesses a loose basket like structure and envelopes many lymphocytes, histiocytes, and plasma cells. Transmission electron microscopy suggests that some of the cells present in tonsillar crypt epithelium contain Birbeck granules and may be Langerhans' cells ${ }^{2}$; this is of interest in relation to the present study, where many cells containing S-100 protein have been shown in branchial cyst epithelium. Such staining suggests that these are Langerhans' cells. This could be of functional significance as these are concerned with antigen handling and presentation to $\mathrm{T}$ lymphocytes. The presence of many $\mathrm{T} 1$ (and fewer $\mathrm{T} 8$ ) bearing lymphocytes within the epithelium emphasises the potential importance of this structure. The histiocytes, also present in large numbers in the branchial cyst epithelium, have previously been shown by enzyme histochemical techniques in both this site $^{3}$ and in tonsillar crypt epithelium..$^{12}$

The frequent finding of lymphatic sinuses in branchial cysts has been emphasised but little in the past. ${ }^{14}$ In the present series of specimens these sinuses were detected most readily by means of immunostaining for cathepsin B, for example. Fewer were seen in conventionally stained sections and this may account for their having been often overlooked in the past. Although the mantle zones of follicles are usually orientated towards the sinuses in lymph nodes, ${ }^{\prime}$ this is not the case in branchial cysts. It could be that the antigenic stimulus arising from the cyst content, whatever its nature, in some way over rides the usual input of antigen via the sinuses. Certainly, the presence of the sinuses themselves is strong evidence in favour of an origin of branchial cysts from lymph nodes. The similarities between the epithelia of the cyst lining and the tonsillar crypts may be coincidental.

With regard to the theory that branchial cysts may have a developmental origin, it is of interest to note 
that in angiofollicular hyperplasia of lymph nodes (Castleman's lesion), long thought to be hamartomatous, there is inversion of the usual helper to suppressor $\mathrm{T}$ cell ratio. ${ }^{15}$ This is not seen in branchial cysts.

We are grateful to Mrs Ruth Fry for typing the manuscript. Mr K Pearman, Mr PM Shenoi, and Mr RM Simons kindly supplied fresh tissues.

\section{References}

' Maran AGD, Buchanan DR. Branchial cysts, sinuses and fistulae. Clin Otolaryngol 1978; 3:77-92.

${ }^{2}$ Howie AJ. Scanning and transmission electron microscopy on the epithelium of human palatine tonsils. J Pathol 1980;130:91-8.

${ }^{3}$ Howie AJ, Crocker J. The lining of branchial cysts studied by electron microscopy and enzyme histochemistry. J Pathol 1981;135: 189-97.

${ }^{4}$ Burnett D, Crocker J, Vaughan ATM. Synthesis of cathepsin B by cells derived from the HL60 promyelocytic leukaemia cell line. J Cell Physiol 1983;115:249-54.

${ }^{5}$ Crocker J, Burnett D, Jones EL. Immunohistochemical demonstration of cathepsin B in the macrophages of benign and malignant lymphoid tissue. J Pathol 1984; 142:87-94.

${ }^{\circ}$ Howie AJ, Burnett D, Crocker J. The distribution of cathepsin B in human tissues. J Pathol (in press).
' Crocker J, Jenkins R, Burnett D. Immunohistochemical demonstration of leucocyte elastase in human tissues.J Clin Pathol 1984;37:1114-8.

${ }^{8}$ Curran RC, Jones EL. Immunoglobulin-containing cells in human tonsils as demonstrated by immunohistochemistry. Clin Exp Immunol 1977;28:103-15.

' Curran RC, Gregory J, Jones EL. The distribution of immunoglobulin and other plasma proteins in human reactive lymph nodes. J Pathol 1982;136:307-32.

${ }^{10}$ Crocker J, Smith PJ. Immunohistochemical localisation of factor VIII-related antigen in Hodgkin's disease. J Clin Pathol 1984;37:37-44.

" Crocker J, Jenkins R, Burnett D. Immunohistochemical localisation of cathepsin G in human tissues. Am J Surg Pathol (in press).

${ }^{12}$ Crocker J. The enzyme histochemistry of lymphomas. Cambridge: University of Cambridge, 1983. MD Thesis.

${ }^{13}$ Crocker J. The enzyme histochemistry of lymphoid and nonlymphoid cells of the human palatine tonsil: a basis for the study of lymphomas. J Pathol 1981;134:81-97.

${ }^{14}$ Howie AJ, Proops DW. The definition of branchial cysts, sinuses and fistulae. Clin Otolaryngol 1982; 7:51-7.

is Jones EL, Crocker J, Gregory J, Guibarra M, Curran RC Angiofollicular lymph node hyperplasia (Castleman's disease): an immunohistochemical and enzyme-histochemical study of the hyaline-vascular form of lesion. J Pathol 1984;144:13147.

Requests for reprints to: Dr J Crocker, Histopathology Department, East Birmingham Hospital, Bordesley Green East, Birmingham B9 5ST, England. 